\title{
EDITORIAL
}

\section{The Triple Challenges of Low and Middle-Income Countries}

\section{Abraham Haileamlak, MD, Professor of Pediatrics and Child Health}

While low and middle-income countries have been struggling with communicable diseases for many years, they are now stuck with noncommunicable diseases and road traffic accidents putting them in triple burden. In recent years, non-communicable diseases such as cardiovascular diseases, mental illnesses, diabetes, chronic obstructive pulmonary diseases and cancers have become an emerging pandemic in low and middle-income countries (1). According to the estimates of the World Health Organization, by 2020, non-communicable diseases will account for 80 percent of the global burden of disease and 70 percent of deaths- the majority of the burden and death being in low and middle-income countries $(2,3)$. The transition from communicable diseases to noncommunicable diseases and road traffic accidents in low and middle-income countries is being catalyzed by the ongoing economic development, urbanization and changing lifestyles (4).

Unless these conditions are curbed timely, they will have deleterious impact on the already stressed healthcare and hamper the struggling economic development (5). As treatment of non-communicable diseases and injuries is very expensive, prevention programs should be the way forward to keep citizens healthy and productive. On the background of limited health infrastructure and meagre health workforce in low and middle-income countries, mid and low-level health workers should serve as backbone for the promotion and prevention services of non-communicable diseases and injuries (6). Although the use of low and midlevel health workers in the prevention of noncommunicable diseases has been proven effective in high income countries, studies revealed that their effectiveness in delivering primary prevention and control in low and middle-income countries is limited $(7,8)$. As this limited effectiveness in low and middle-income countries could be because of poor implementation, proper system creation should be emphasized to yield better results.

The current issue, the first regular issue for the year 2018, contains an editorial, nine original articles, four case reports and a letter to the editor. The editorial, four of the original articles, two of the case reports and the letter to the editor researched on non-communicable diseases. The other articles and case reports focus on various topics.

I invite readers to go through these articles and appreciate or utilize the contents. I also encourage readers to forward comments and suggestions to the editor or the corresponding authors.

\section{REFERENCES}

1. Terzic A, Waldman S. Chronic diseases: the emerging pandemic. Clinical and translational science. 2011;4(3):225-226. doi: 10.1111/j.1752-8062.2011.00295.x.

2. Mathers CD, Loncar D. Projections of global mortality and burden of disease from 2002 to 2030. PLoS Med. 2006;3(11):e442. doi: 10.1371/journal.pmed.0030442.

3. World Health Organization: Global action plan for the prevention and control of noncommunicable diseases 2013-2020. In. Edited by WHO. Geneva, Switzerland: WHO; 2013: 55.

4. Hancock C, Kingo L, Raynaud O. The private sector, international development and NCDs. Glob Health. 2011;7(1):1-11. doi: 10.1186/1744-8603-7-23.

5. Beaglehole R, Bonita R, Horton R, Adams C, Alleyne G, Asaria P, Baugh V, Bekedam H, Billo N, Casswell S. Priority actions for the non-communicable disease crisis. Lancet. 2011;377(9775):1438-1447. doi: 10.1016/S0140-6736(11)60393-0. 
6. Bhutta ZA, Lassi ZS, Pariyo G, Huicho L. WHO Global Health Workforce Alliance. Global Experience of Community Health Workers for Delivery of Health-Related Millennium Development Goals: A Systematic Review, Country Case Studies, and Recommendations for Integration into National Health Systems. Geneva: 2010.

7. Maher D, Ford N, Unwin N. Priorities for developing countries in the global response to non-communicable diseases. Globalization and Health. 2012;8(1):1-8. pmid:22686126

8. Lin JS, O'Connor EA, Evans CV, Senger CA, Rowland MG, Groom HC. U.S. Preventive Services Task Force Evidence Syntheses, formerly Systematic Evidence Reviews. Behavioral Counseling to Promote a Healthy Lifestyle for Cardiovascular Disease Prevention in Persons With Cardiovascular Risk Factors: An Updated Systematic Evidence Review for the US Preventive Services Task Force. Rockville (MD): Agency for Healthcare Research and Quality (US); 2014. 